\section{Certified sickness absence: does the 'fit-note' work?}

\author{
R M Agius, ${ }^{1,2}$ L J Hussey $^{1}$
}

Long-term sickness absence is costly for employers, workers and society in general. Besides the economic benefits, enabling timely rehabilitation of employees back to work is also intended to improve their physical well-being and self-esteem. ${ }^{1}$ One of the measures recommended in the Black Report to help achieve these aims was the introduction (in the UK) of the 'fit-note' in $2010 .^{2}$ This fit-note was intended to replace, at least in part, stark statements that a worker was too 'sick' to work by qualified statements of fitness provided certain reasonable workplace adjustments (such as a graded return to work) were made.

The paper by Gabbay et $a l^{3}$ evaluates the effects of the introduction of the fit-note by examining sickness absence data collected in two separate studies, separated by a decade, and conducted before and after the introduction of the fit-note. The comparison was based on seven general medical practices which were common to the two studies of a larger set of 68 UK practices. ${ }^{4}$ Gabbay et al showed an increase in the total number of certificated absences issued in the seven common practices after the introduction of the fit-note, and especially an even greater increase in the number of those certificates associated with mental illhealth diagnoses. They showed that $8.5 \%$ of fit-note certificates were qualified by workplace adjustment advice, thus indicating that in the practices which were compared the crude number of certificates giving unqualified sickness certification was about $20 \%$ higher after the fit-note introduction.

As in other studies of the fit-note it is not known whether the employers of individuals provided with qualified 'fit' advice

\footnotetext{
${ }^{1}$ Faculty of Medical and Human Sciences, Centre for Occupational and Environmental Health, Centre for Epidemiology, Institute of Population Health, The University of Manchester, Manchester, UK; ${ }^{2}$ Occupational Health Department, Manchester Royal Infirmary, Manchester, UK

Correspondence to Professor R M Agius, Faculty of Medical and Human Sciences, Centre for Occupational and Environmental Health, Centre for Epidemiology, Institute of Population Health, The University of Manchester, Manchester M139PL, UK;

raymond.agius@manchester.ac.uk
}

are able to implement the suggested workplace adjustments and thus enable the patient to work. Moreover, as acknowledged by the authors, the denominator is unknown, that is, any change in size and characteristics of the practices' patient population in the 10 years between the studies was not determinable. Therefore it is difficult to ascertain whether the fit-note has resulted in a change in the likelihood of patients being determined fit for work. Other researchers examined the effects of the fit-note introduction on the proportionate distribution of cases of workrelated ill-health certified sick. They investigated the proportion of all cases within the study who were certified sick before and after the introduction of the fit-note (4 years before and 3 years after) and found no significant decrease in the proportion of incident cases who were certified as unfit to work. Despite the suggested increase in certificates/episodes Gabbay et al showed that in the post fit-note period there was a highly significant reduction in the overall risk of sickness absence episodes exceeding 12 weeks. However, the effect was very variable with no evidence of change in any direction in four of the seven practices. Further work is needed to evaluate the effect of fit-note training of the general practitioners (GPs) on the certification outcomes.

Gabbay et al also examined, in the larger data set, the relative effects of a number of factors (patient, GP and practice) on the length of sickness absence. As described in the authors' previous work and in results from other studies, cases of mental illhealth were responsible for the highest proportion of fit-notes issued, followed by musculoskeletal disorders. ${ }^{45} 6$ 'May be fit' advice was less frequently included on fitnotes issued to patients with psychological diagnoses, and this is consistent with results examining the fit-note advice offered to patients in other work.

While not finding evidence suggesting a reduction in the likelihood of being certified unfit to work, Gabbay's study contributed to knowledge by studying the length of certified sickness absence. Many studies report on the rate of certification but are unable to collect information on the length of absence. ${ }^{6}$ Research on the length of sickness absence in the UK has been difficult largely due to the lack of routinely collected data at general practice level. ${ }^{4}$ It had been planned to start introducing the 'Electronic fit note' (eMed3) in July 2012 with the ultimate aim of saving and transferring anonymised fit-note data to the Department of Work and Pensions (DWP). However, handwritten fit-notes are still used by GPs and this data collection remains unsystematic and incomplete. ${ }^{8} 9$ Moreover, knowledge and information about the patients' work is often lacking. Gabbay et al asked GPs to state whether the patient was in paid employment or unemployed; but this information was not recorded in $60 \%$ of the fit-notes. This is consistent with findings from other work showing that essential occupational information is often not recorded by the GP. ${ }^{10}$

While it is essential to thoroughly evaluate national interventions such as the fit-note these interventions are sometimes introduced without provision for rigorous evaluation based on a controlled pilot exercise. Moreover in evaluating such interventions, especially when uncontrolled, the 'before and after' intervals should be as short as possible to reduce potential bias from concomitant trends and changes in denominators, participants or their behaviour. The DWP has recently launched the Fit for Work Service for patients certified off work because of sickness for more than four weeks. ${ }^{11}$ Under the scheme, GPs (or possibly employers) would refer employees for a work-focused occupational health assessment. This is intended to identify the issues preventing an employee from returning to work and draw up a plan for them, their GP and their employer, recommending how the employee can be helped back to work more quickly. It is hoped that small businesses, which do not generally have occupational health services, would particularly benefit. Gabbay et al found that $47 \%$ of certificated episodes lasted longer than 3 weeks, and therefore suggested that considerable resources would be required to operate the Fit For Work Service effectively.

In conclusion-the 'jury is still out' as regards a corroborated, valid and comprehensive assessment of the effect of the fit-note. Moreover a thorough and systematic evaluation of the effects of the Fit for Work Service, is much needed especially considering its potentially very large economic implications as well as effects on well-being.

Competing interests None. 
Provenance and peer review Commissioned; internally peer reviewed.
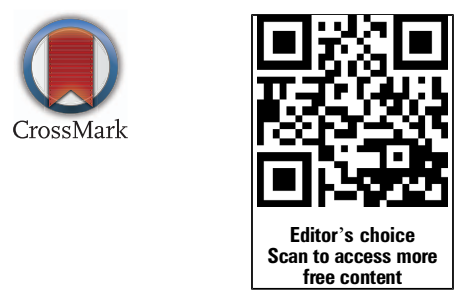

To cite Agius RM, Hussey LJ. Occup Environ Med 2015;72:463-464.

Received 23 December 2014

Accepted 3 February 2015

Published Online First 24 February 2015

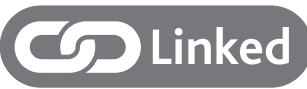

http://dx.doi.org/10.1136/oemed-2014-102307
Occup Environ Med 2015;72:463-464.

doi:10.1136/oemed-2014-102685

\section{REFERENCES}

1 Waddell G, Burton AK. Is work good for your health and well-being? London: TSO, 2006. https://www. gov.uk/government/uploads/system/uploads/ attachment_data/file/214326/ hwwb-is-work-good-for-you.pdf

2 Black C. Working for a healthier tomorrow. London: TSO, 2008. https://www.gov.uk/government/uploads/ system/uploads/attachment_data/file/209782/ hwwb-working-for-a-healthier-tomorrow.pdf

3 Gabbay M, Sheils C, Hillage J. Factors associated with the length of fit-note certified sickness episodes in the UK. Occup Environ Med 2015;72:467-75.

4 Sheils C, Gabbay M. Patient, clinician, and general practice factors in long-term certified sickness. Scand J Public Health 2007;35:250-6.

5 Hussey L, Turner S, Thorley K, et al. Work-related sickness absence as reported by UK general practitioners. Occup Med 2012;62:105-11.
6 Wynne-Jones G, Mallen CD, Mottram S, et al. Identification of UK sickness certification rates, standardised for age and sex. Br J Gen Pract 2009:59:510-16.

7 Tellnes G, Svendsen KOB, Bruusgaard D, et al. The incidence of sickness certification. Scan J Prim Health 1989;7:111-17.

8 Improving health and work: changing lives-The Government's Response to Dame Carol Black's Review of the health of Britain's working-age population. 2008. https://www.gov.uk/government/ uploads/system/uploads/attachment_data/file/ 210858/hwwb-improving-health-and-work-changinglives.pdf

9 Electronic fit note (eMed)—fact sheet for GPs. DWP 2014. http://www.gpcwm.org.uk/wp-content/ uploads/2011/05/Fit-Notes-Electronic-Fit-Note-FactSheet-for-GPs-June-2013.pdf

10 Richards-Taylor A, Keay J, Thorley K. Do GPs record the occupation of their patients? Occup Med 2013;63:138-40.

11 The Health \& Work Service. GOV.UK. 2014. https:/l www.gov.uk/government/uploads/system/uploads/ attachment_data/file/362480/fit-for-work.pdf 